\title{
El sagrado codo nilótico en las iglesias alejandrinas del siglo IV
}

\author{
José Ramón AJa SÁNCHeZ \\ Universidad de Cantabria \\ ajajr@unican.es
}

El milenario culto al Nilo fue quizás el único que escapó a la intransigencia religiosa cristiana sin perder su esencia vernácula más genuina. En Alejandría estuvo asociado al culto de Serapis, justo por la imbricación de la naturaleza del dios Neilos con la de Osiris, una de las deidades que desde épocas más tempranas estuvieron presentes en el mismo centro de la cosmogonía egipcia relacionada con la crecida del Nilo, y por encarnar además - tutelando a Hâpi, al pretérito genio fecundante del río - la potencia mágica y regenerativa de las aguas desbordadas cada año. Desde luego, a finales del siglo IV, Rufino de Aquileya se hacía eco de la creencia popular según la cual Serapis (ya no Osiris) era el artífice de la crecida anual $\left(H E\right.$, II. $\left.30^{1}\right)$. Tal fue la razón de que el clérigo cristiano creyera - correctamente - que el Serapieion alejandrino tenía, entre otras muchas atribuciones, la de supervisar la progresión de ésta, medir su altura máxima, y calcular sus beneficios. Incluso fuera de Egipto, Serapis era algunas veces considerado Neilagôgos, y algunas inscripciones vinculaban a los devotos serapeos con el culto a Neilos, pues participaban de forma activa en los sacrificios y festivales dedicados a la divinidad fluvial².

* Recebido em 13-12-2014; aceite para publicação em 30-04-2015.

${ }^{1}$ Las citas que en adelante haremos a la Historia Eclesiástica de Rufino siguen la edición de J.-P. Migne, PL 21 cols. 461-540. Como es sabido, el monje cristiano añadió a la HE de Eusebio de Cesarea dos libros redactados por él mismo. En el libro I refundió los libros 9 y 10 de la obra del obispo palestino, y en el II cubrió el periodo de los años 325 a 395. A este último libro (el "XI" en la obra de Eusebio) van referidas las citas insertas en este trabajo.

2 Ejemplos en M. Malaise, "La diffusion des cultes isiaques: un problème de terminologie et de critique”, en L. Bricault, M. J. Versluys, P. G. P. Meyboom (eds.), Nile into Tiber: Egypt in the Roman World (Proceedings of the III International Conference of Isis Studies, Leiden, May 11-14, 2005), Leiden, 2007, pp. 19-39, cit. 26. El Serapieion alejandrino seguía teniendo en el siglo IV la grandeza y suntuosidad del pasado, tal y como evidencian los comentarios que sobre el mismo dejaron por escrito algunos coetáneos que lo conocieron in situ, entre otros Amiano Marcelino (XXII.16.12), un discípulo de Libanio (vid. Aphthonio, Progymnasmata, 12, ed. H. RABe, Leipzig, 1926, pp. 38-41), Rufino de Aquileya (HE, II.23) y un anónimo visitante pagano (Expositio Totius Mundi et Gentium, 35). Además, como es conocido, el santuario se salvó de la destrucción generalizada que en marzo del año 298 sufrió Alejandría a manos de las tropas del emperador Diocleciano con ocasión de la sofocación de la revuelta de Lucio Domicio Domiciano, destrucción de la que no se libraron ni la Biblioteca Filial (heredera de la pretérita gran Biblioteca Real) ni el Mouseion. Ello hizo que el templo de Serapis se convirtiera a partir de entonces - si no lo era ya - en algo bastante más relevante que un espacio de culto, en concreto, en una especie de reservorio ("universidad" 
Fue pues la creencia generalizada (hasta fechas muy tardías) de que tanto Neilos como Serapis debían garantizar la llegada anual de las nutritivas aguas, la que explica que el santuario del segundo en Alejandría fuera, no sólo el que centralizaba el culto al Nilo antes del acceso al poder el emperador Constantino, sino también el lugar donde se guardaba y custodiaba el arquetipo ceremonial del sacrosanto "codo nilótico", el cual era sacado en procesión varios días al año coincidiendo con los festivales de la crecida ${ }^{3}$.

El propio Rufino (HE, II.30) mencionó que el artefacto medidor fue trasladado desde el templo de Serapis a una iglesia alejandrina consagrada al "Señor de las Aguas" ("Ulna ipsa, id est, aquae mensura, quam $\pi \tilde{\eta} \chi v v$ vocant, ad aquarum dominum in ecclesiam coepta deferri"), relacionando este evento con la época inmediatamente posterior al cierre del templo pagano (año 391 ${ }^{4}$ ). Sin embargo, unos cincuenta años después de la publicación de la historia eclesiástica de Rufino, el también cristiano Sócrates (I.18.2) se refirió a un traslado que tuvo lugar mucho antes, cuando el emperador Constantino, poco después del año 324, ordenó al obispo de Alejandría (Alejandro) que deposi-

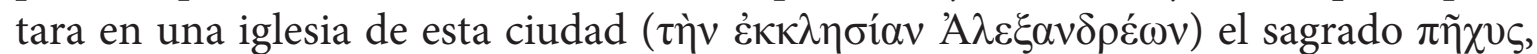
el cual "hasta entonces había estado guardado en el templo de Serapis"5. Sozomeno, que resumió la misma noticia de Sócrates, aportó un punto de confusión al tema al

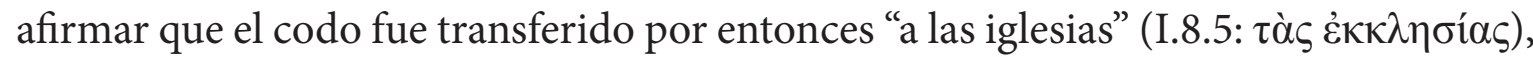
pero añadió, esta vez por cuenta propia, un detalle importante: décadas adelante, el emperador Juliano el Apóstata lo devolvió al santuario de Serapis (V.3.3). Finalmente, un cronista del siglo VIII, el monje Teófanes, registraba que "Constantino legisló que en Egipto un codo [medidor] de la crecida del Nilo fue ofrecido a la Iglesia y no al Serapieion como era la costumbre pagana" (Chron. 16.24, ann. 317/318, PG I: 23).

Así pues, las fuentes parecen referirse a varios traslados acaecidos en fechas y circunstancias diferentes, estando en ellos involucradas al menos dos iglesias cristianas.

y "museo" a la vez) de la sabiduría pagana coetánea, o si se quiere, en un "cajón de sastre" donde acabó siendo guardado y cultivado mucho del patrimonio religioso y de la sabiduría del paganismo greco-egipcio.

${ }^{3}$ Cf. F. E. Engreen, "The Nilometer in the Serapeum at Alexandria", Medievalia et Humanistica, 1, 1943, 3-13; A. Hermann, "Der Nil und die Christen", JbAC, 2, 1959, 30-69, cit. 33-35; F. Thelamon, Païens et chrétiens au IVe siècle: L'apport de l'Histoire ecclesiastique de Rufin d'Aquilee, Paris, 1981, pp. 274-275; Ch. HaAs, Alexandria in Late Antiquity. Topography and Social Conflict, Baltimore, 1997, p. 166). Recordemos que el codo nilótico, al que las fuentes griegas se refirieron con el término $\pi \tilde{\eta} \chi 0 \varsigma$ y las romanas con el de ulna, era un utensilio nilométrico generalmente elaborado en madera que representaba una unidad de longitud arquetípica, esto es, el "codo" egipcio, equivalente a unos $52,5 \mathrm{~cm}$, si bien esta longitud parece haber variado a lo largo del tiempo por razones no del todo claras (J.-C. Goyon, J.-C. Golvin, C. Simon-Boidot, La construction pharaonique du moyen empire à lépoque greco-romaine: contexte et principes tecnologiques, Paris, 2004, pp. 92-97 y 385-388; al respecto ver también D. BonneAu, "Le nilomètre: aspect technique", en L'homme et l'eau en Méditerranée et au Proche-Orient, III: L'eau dans les techniques (Travaux de la Maison de l'Orient, 11), Lyon, 1986, pp. 65-73. Aparte de los codos de uso corriente, los había votivos o ceremoniales, elaborados en materiales nobles o en madera recubierta de láminas de oro. Se mantenían guardados en el espacio sagrado de los templos, y en las referencias escritas eran acompañados frecuentemente con el calificativo divino ( $\theta \varepsilon i ̃ o s)$.

${ }^{4} \mathrm{La}$ fecha concreta (no registrada en las fuentes del suceso) es difícil de establecer. A. H. M. Jones (Later Roman Empire, 284-602. A Social and Administrative Survey, 2 vols., Oxford, 1973, p. 1102 n. 77) y F. Thelamon (op. cit., p. 254) propusieron que el suceso pudo ocurrir a finales de junio del 391, o bien en noviembre del mismo año.

${ }^{5}$ A. MARTIN ("Les premiers siècles du christianisme à Alexandrie, essai de topographie religieuse (IIIe-IVe siècles)", REAug, 30, 1984, 211-225, cit. 219) propuso que el traslado tuvo lugar durante la fiesta de la crecida del año 326. 
Por el momento, demos por bueno el hecho de que hubo un traslado del venerado codo en época de Constantino (Serapieion $\rightarrow$ iglesia), que hubo otro en época de Juliano (iglesia $\rightarrow$ Serapieion), y que hubo otro más después del cierre del santuario pagano (Serapieion $\rightarrow$ iglesia).

En todo caso, ninguno de los escritores citados precisó suficientemente la identificación de las iglesias cristianas a las que fue trasladado el artefacto nilométrico en cada ocasión, salvo quizá la indicación que hizo Rufino sobre la advocación de la iglesia a la que él mismo se refirió. Planteadas así las cosas, la cuestión de fondo es poder saber cuándo el codo nilótico fue trasladado por primera vez, a qué iglesia en concreto, y qué traslados ulteriores hubo (si los hubo) y adónde. Algunas respuestas a estas cuestiones se pueden encontrar.

Varias circunstancias significativas pueden ayudarnos en la tarea. La primera es que, según una tradición recogida en la tardía crónica del obispo alejandrino Eutiquio (Annales, 300 y 433-435, PG III, 975c y 1005ab) ${ }^{6}$, esa iglesia muy probablemente había sido en origen un templo consagrado a Cronos/Saturno, quizás el primer santuario pagano que sufrió una reconversión religiosa en Alejandría, en concreto entre los años 324-326 y por obra del obispo Alejandro (313-326). La existencia de un culto a Cronos en la metrópoli egipcia está desde luego atestiguada en las fuentes coetáneas, pero se ha dudado de la identidad de la iglesia que fue acomodada entre las estructuras de ese templo y de la fecha en la que fue hecha esta reconversión. Thelamon aportó al tema un dato importante: según una tradición árabe, la nueva iglesia se consagró a San Miguel en razón de que en las cercanías de la misma se celebraba una fiesta dedicada a este arcángel ${ }^{8}$. El investigador francés creía a su vez que había evidencia suficiente para pensar que esta fiesta cristiana habría sustituido a una pagana consagrada o bien a Cronos (las Kronia/Saturnales) o bien a Thot/Hermes (ibid. 236 y 277 n. 101), y que el obispo Alejandro había conseguido convencer a la población para realizar la reconversión del festival, probablemente permitiendo que se conservaran parte de los elementos y ceremonias de la pretérita fiesta pagana.

En todo caso, hoy parece generalizada la creencia de que la tradición procedente de los Annales de Eutiquio es cierta, y que como propuso Thelamon, la nueva iglesia - reconvertida a partir de un templo pagano - habría estado consagrada al arcángel san Miguel. Con posterioridad adoptó el nombre "de Alejandro" en honor del obispo que la había promovido originalmente?

${ }^{6}$ Se trata de un obispo melquita (932-940), esto es, de aquellos que se mantuvieron fieles al Concilio de Calcedonia después del cisma monofisita del año 535 (patriarcas ortodoxos hasta nuestros días).

${ }^{7}$ Este debate puede seguirse en A. Martin, "Les premiers siècles du christianisme", loc. cit., 218 n. 48; Idem, Athanase d'Alexandrie et l'église d'Egypte au IVe siècle (328-373), Roma, 1996, pp. 149-151 n. 152; y J. McKenzie, The Architecture of Alexandria and Egypt, c. 300 BC to AD 700, New Haven / Londres, 2007, pp. 407 n. 25 y $411-412$ n. 173.

${ }^{8}$ F. Thelamon, op. cit., p. 236.

${ }^{9}$ En efecto, estas hipótesis son actualmente aceptadas por autores que conocen bien la historia y topografía de la metrópoli egipcia, entre otros, O. F. A. Meinardus, "Ancient and Modern Curches of Alexandria", Oriens Christiana, 48, 1964, 163-179, cit. 164; A. Martin, "Les premiers siècles du christianisme”, loc. cit., 218-219; Idem, op. cit., pp. 149-151; Сн. HAAs, op. cit., pp. 166 y 208-211; J. GASCOU, "Les 
La segunda circunstancia que nos puede ayudar es que la propia figura del arcángel san Miguel a la que se asocia la referida iglesia no nos parece en absoluto un detalle neutro, aunque la mayoría de los autores que lo mencionan no parecen reparar lo suficiente en él. En el imaginario cristiano este arcángel sustituyó al dios Thot, el cual tenía una estrecha relación con la inundación anual, justo por su capacidad de manejar y registrar cifras o de calcular fechas, lo que a su vez explica su presencia secular en el panteón vinculado a la Primera Catarata y su estrecha relación con la tríada de Elefantina ${ }^{10}$. Por su parte, la tradicional labor de "mediación" del arcángel san Miguel en lo que a la crecida anual se refiere ha quedado bien reflejada en el calendario copto actual, que le dedica una conmemoración mensual ${ }^{11}$, y también, de forma muy plástica, en algunos amuletos de época romano-tardía que le asociaban con el desbordamiento periódico del $\mathrm{Nilo}^{12}$.

Y tercera circunstancia: la advocación que, según Rufino, tenía el templo cristiano donde fue alojado el codo nilótico ceremonial - "Señor de las Aguas", aquarum dominum - tiene también una remembranza pagana clara ${ }^{13}$; sin embargo, para los cristianos era también una analogía familiar aplicada a Dios ${ }^{14}$. No obstante, lo que realmente nos resulta llamativo de esta advocación no es tanto su naturaleza pagana o cristiana, sino el hecho de que el apelativo "Señor de las Aguas Frescas" ( $n b k b h w$ ) le fuera atribuido tradicionalmente a una de las antiguas deidades egipcias responsables de la inundación anual, en concreto al dios Khnum ( $\underline{h n m w} k b h \underline{h w}$, esto es, Khnum

églises d'Alexandrie: questions de méthode", en C. Décobert, J.-Y. Empereur (eds.), Alexandrie médièvale, vol. I, Cairo, 1998, pp. 23-44; P. Grossmann, Christliche Architektur in Ägypten, Leiden, 2002, p. 195; y H. Reinhard Seeliger, K. Krumeich, Archäologie der antiken Bischofssitze, I: Spätantike Bischofssitze Ägyptens, Wiesbaden, 2007, pp. 49-50. Por su parte, J. McKenzie, op. cit., pp. 240-242, sin rechazar esas hipótesis, se centra en otras incertidumbres asociadas a este edificio cristiano.

${ }^{10}$ Sobre los atributos de "mediación" de san Miguel y de Thot, y sobre la mutación de éste en el primero, ver A. MARTin (op. cit., p. 150 y n. 155) y L. KÁKOsy ("Problems of the Thoth-Cult in Roman Egypt", Acta Antiqua Academiae Scientiarum Hungaricae, 15, 1963, 123-128). La relación de Thot con la tríada Elefantina se evidencia bien en el trabajo de A. GASsE, V. Rondot, Les inscriptions de Séhel, El Cairo, 2007, pp. 257-258 y n. ${ }^{\circ}$ 414. Otra clase de asociaciones del arcángel san Miguel con el paganismo están documentadas en J. VAN DER VLIET, "Spätantikes Heidentum im Ägypten im Spiegel der koptischen Literatur", en D. Willers et al. (eds.), Riggisberger Berichte, vol. 1: Begegnung von Heidentum und Christentum im spätantiken Ägypten, Riggisberger, 1993, pp. 99-130, cit. 114 y 116.

${ }^{11}$ En concreto, en los días centrales de cada uno de los meses del año copto; ver este calendario en O. F. A. Meinardus, Two Thousand Years of Coptic Christianity, El Cairo/Nueva York (reimpr. ed. orig. de 1999), pp. 286 y ss; la inclusión del arcángel en él y en fechas significativas del inicio de la crecida, en

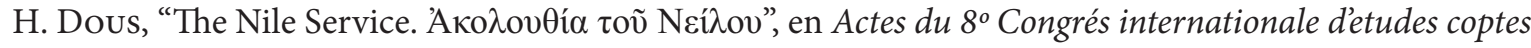
(Paris, 2004), Orientalia lovaniensia analecta, 163, Lovaina, 2007, pp. 425-438: 425 y ss.

${ }_{12}$ Cf. D. Wortmann, "Kosmogonie und Nilflut. Studien zu einigen Typen magischer Gemmen griechisch-römischer Zeit aus Ägypten“, Bonner Jahrbücher, Kevelaer-Colonia / Graz, 1966, pp. 62-112.

${ }^{13}$ Apunta a la encarnación divina del río, Neilos/Serapis, o a cualquier deidad asociada al mismo. Sabemos de otros documentos que utilizaron epítetos similares referidos al mismo sujeto, p. ej., Tíbulo (I.7-23: aquarum dominus), o el P. Lond (239.15: $\tau \tilde{\omega} v \pi \circ \tau \alpha \mu \tilde{\omega} v \beta \alpha \sigma \lambda \lambda \varepsilon u ́ s)$; en época lágida se empleaba

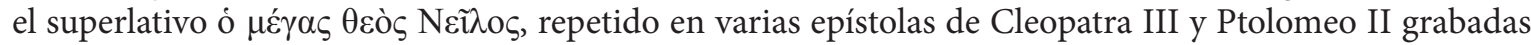
sobre estelas (S. Baкноuм, Deux égyptiens à Alexandrie sous les Antonins. Recherches numismatiques et historiques, Paris, 2002, pp. 88-89 y n. 15), o en una inscripción de Ptolomeo IX Soter II procedente de Elefantina (cf. OGI 168.6, apud A. Bernand, De Thebes à Syène, Paris, 1989, p. 328 y n. ${ }^{\circ} 244$ ).

${ }^{14}$ Cf. Gn 1.9-10; Ex 15.8; Ps 33.7 y 78.13; Jb 38.8, Jr 17.13, etc. 
"[Señor] de las Aguas Frescas")15, o también el epíteto equivalente "[Khnum] el que preside las Aguas Frescas - o la Catarata - [knty $k b h w$ w]"16. En relación a esta deidad, el apelativo concuerda con el "agua fresca" del río que era utilizada por los alfareros, sobreentendiendo en el dios su encarnación como Gran Alfarero de la Humanidad (Creador de la misma), pero también con la cualidad sagrada y el poder mágico de las aguas frescas que emanaban entre las rocas de la Primera Catarata dando paso a la crecida anual del Nilo. Así pues, Rufino evidencia en este sentido, no sólo que el último traslado del codo se pudo realizar después del 391 desde el Serapieion a una iglesia cristiana, sino también que ésta tenía una advocación equiparable a la que tuvo aquella otra en la que el codo estuvo por vez primera alojado en época constantiniana ( san Miguel), ya que ambas iglesias evocan epítetos, asociaciones y entidades divinas relacionadas con el imaginario pagano relativo al desbordamiento anual del Nilo.

Ahora bien, la advocación de la iglesia del "Señor de las Aguas" a la que aludió Rufino ¿era producto de una transferencia religiosa pagana como la que acabamos de ver, o más bien estaba referida al Dios cristiano? Es muy complicado dar una respuesta a esta pregunta, pero en el caso de apostar por la segunda posibilidad, se nos abre otra cuestión muy interesante.

Como ya dijimos, el monje cristiano se había hecho eco de que las creencias paganas atribuían a Serapis la cualidad de crear la crecida periódica (HE, II.30: "incrementi aquarum et inundationis auctor"), de manera que es posible que, mencionando la advocación de la iglesia a la que fue transferido el codo inmediatamente después del asalto y cierre cristiano del Serapieion, quisiera subrayar que era Dios el auténtico aquarum dominus (no Serapis). Ello no hace sino confirmarnos en la idea de que los creyentes paganos egipcios, griegos y romanos, así como también los cristianos, desconociendo fehacientemente las causas verdaderas - tangibles y físicas - de la crecida nilótica, veían en la Providencia divina la génesis de un fenómeno natural cuya ubicación y fenomenología ninguno de ellos llegó a conocer o a comprender nunca ${ }^{17}$.

15 Cf. J. BAInes, Fecundity figures. Egyptian personification and the iconology of a genre, Oxford, 2001, p. 312 y fig. 175 (ed. orig. 1985).

${ }^{16}$ Cf. S. Bickel, "Liconographie du dieu Khnoum", BIFAO, 91, 1991, 55-67. Khnum como Señor absoluto de la Primera Catarata, en G. ZAKI, Le Premier Nome de haute-Égypte du IIIe siècle avant J.-C. au VIIe siècle après J.-C. d'après les sources hiéroglyphiques des temples ptolémaïques et romains, Turnhout, 2009 , pp. 206-224. Por su parte, la expresión agua/s fresca/s ( $k b h / k b h w)$ estaba en estos casos referida a las aguas de la crecida nilótica, la cual tuvo siempre un componente trascendente muy notable en el ámbito del culto ordinario de los templos, o en el de las ofrendas y prácticas funerarias en general (cf. J. R. AJA SÁnchez, "Qebeh, Qebehet and 'cool water' in Peye's 'Victory Stela' ”, CdE, 87:2, fasc. 174, 2012, 218-232).

17 Por ejemplo, Lucano (De bello civile, X.263-268) decía: “[Algunas aguas] brotan en el mundo sin ninguna intervención divina; pero algunas otras, en el momento mismo de la formación del mundo, comenzaron a existir en su conjunto, y éstas [las del Nilo] son las que aquel creador y artífice del universo tiene sometidas a un régimen determinado. También Elio Aristides (Or., XXXVI.104) explicaba: "Yo, como persona que podría atribuir y otorgar todo a Zeus, también podría conceder que el Nilo viene del cielo y que es obra de Zeus"; y más adelante, ibid. 120: "Cuando la ley divina hace y obliga que el río crezca, entonces [...] aquellas arenas y las aberturas de la tierra [...] no llegan a constituir impedimento para él". Estos autores no hacían en el fondo sino seguir una línea de razonamiento religiosa que ya existía en el Egipto dinástico. Así, en los pretéritos Textos de los Sarcófagos (462d-464f), es posible leer: "He creado [yo, Khnum, el Creador de la Humanidad] la gran inundación [del Nilo], para que tanto el pobre como el rico 
El rastro de esta idea trascendente sobre la génesis - divina - de la crecida desde una óptica cristiana es también fácil de seguir. Digamos a este respecto que algunos traductores recientes de la Chronographia de Teófanes interpretan su comentario sobre el traslado del codo a una iglesia (vid. supra) en el sentido de que el clérigo bizantino deseaba demostrar que para el emperador la crecida del Nilo era una obra de la Providencia y no de la voluntad de Serapis ${ }^{18}$. No estamos del todo seguros de que el comentario de aquél pueda interpretarse hasta este extremo, pero sin duda esa idea estaba instalada en la literatura cristiana desde antiguo, así que bien pudo estar presente en la mente de Teófanes cuando hizo su comentario. Ciertamente, la misma idea está expresada en la biografía que el monje egipcio Besa escribió en la segunda mitad del siglo V sobre su paisano y maestro el apa Shenoute ${ }^{19}$, que urgía a Dios para que no retrasara la crecida anual, ya que de él dependía que llegara a tiempo. También lo está en la propia noticia de Sócrates ya citada supra, pues una vez comentado el traslado del codo a una iglesia, el historiador eclesiástico terminaba diciendo:

A pesar de que ellos [los paganos] predijeron que el Nilo no se desbordaría a causa de la cólera de Serapis [por el traslado del codo a una iglesia], la crecida del río tuvo lugar al año siguiente, y posteriormente también, como siempre ha ocurrido, de manera que los hechos demuestran que no es a causa de una práctica religiosa que se produce la crecida del Nilo sino en razón de los designios

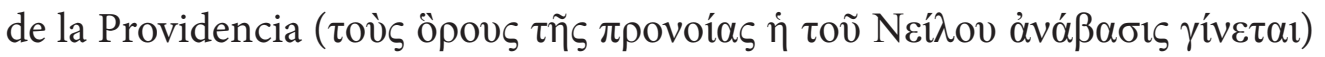

Igualmente, Eusebio de Cesarea ya había expresado la misma idea en la década de los años 330 cuando expuso las leyes anti-paganas de Constantino.

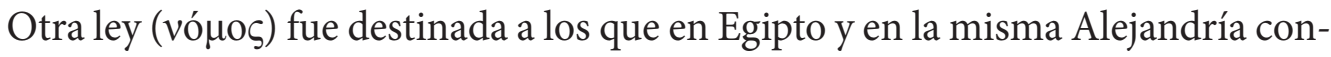
servan la costumbre de venerar a su río mediante hombres afeminados ( $\dot{\alpha} v \delta \rho \tilde{\omega} v$ $\dot{\varepsilon} \kappa \tau \varepsilon \theta \eta \lambda \nu \mu \mu \varepsilon ́ v \omega v)$; dicha ley mandaba que toda aquella ralea de hermafroditas $(\dot{\alpha} v \delta \rho \gamma \gamma v \omega \omega v)$ fuera exterminada como algo espurio, y que en ningún lugar pudieran verse seres tan patológicamente afectados de esa lascivia. Y como los supersticiosos [paganos] dieron en pensar que ya no iba a fluir el río como de costumbre, Dios, obrando de consuno con la ley del emperador, operó todo al revés de cuanto esperaban [aquéllos]; pues ya no estaban los que contaminaban las ciudades con su impudicia, y el río, como si se le hubiera purificado la comarca, afluyó más crecido que nunca, y subiendo con su rico caudal irrigó los labrantíos, enseñando con los hechos a los hombres la imperiosa necesidad de rehuir a gente impía y descabellada, y que sólo a Dios, dispensador de todo

se aproveche de ella". El debate sobre el grado de conocimiento grecorromano de la ubicación y génesis de la crecida nilótica (en las montañas de Etiopía) puede verse ahora en J. R. AJA Sánchez, Aguas mágicas. El Nilo en la memoria y la religiosidad del Mundo Antiguo, Madrid, 2015, caps. 2 y 3.

${ }^{18}$ Cf. C. Mango, R. Scott (trad. y com.), The Chronicle of Theophanes Confessor. Byzantine and Near Eastern History AD 284-813, Oxford, 2006, p. 28 n. 6.

19 Besa, Sinuthii archimandritae vita et opera omnia, vol. III: 102-106 y 122 (ed. H. WiesmanN, CSCO, 96, Lovaina, 1965. 
bien, debían [los egipcios] atribuir la causa de eventos tan bienhechores [a saber, la periódica crecida nilótica].

(Vit. Const., IV.25.2-3, trad. M. Gurruchaga)

Es decir, en todos estos escritores - incluidos probablemente Rufino y Teófanes - estaba muy presente la idea trascendente de que la Providencia, no Serapis ni Neilos, cuidaba de que el Nilo creciese y se desbordara todos los años. Y si esto fue realmente así, tendríamos que admitir que el título "Señor de las Aguas" adscrito a la iglesia cristiana mencionada por el monje Rufino estaba referido inequívocamente al Dios cristiano (y no a ninguna otra pretérita entidad divina pagana).

Por lo demás, ya habrá observado el lector que el comentario de Eusebio es igual de relevante para evidenciar, tanto la perduración del culto al Nilo (justo cuando señala que la orden imperial en cuestión apuntaba contra el clero de hermafroditas que todavía lo atendía), como para ofrecernos el marco ideológico y legislativo al que luego se refirieron Sócrates, Sozomeno y Teófanes, marco éste que amparó la decisión constantiniana de sacar el sagrado artefacto del Serapieion y guardarlo en una iglesia, señalando con este acto simbólico que él mismo sería el primero en cumplir sus propias leyes anti-paganas ${ }^{20}$. A este respecto cabría pensar incluso que la recién inaugurada iglesia pudo ser favorecida intencionadamente por el emperador cuando ordenó trasladar a ella el arquetipo del codo nilótico desde el templo de Serapis (probablemente a instancias del propio obispo Alejandro y del marco legislativo apuntado).

En otro orden de cosas, hay que tener en cuenta que cuando la iglesia de san Miguel fue acomodada entre las estructuras del templo de Cronos (si éste fue realmente el método de creación de la misma), pasó a convertirse en la más grande de la ciudad, hasta que años más tarde, pero no antes de la mitad del siglo IV, se ubicó otra dentro del enorme témenos del Kaisareion (Caesareum de Augusto) consagrada al Señor (Kyriakon/Dominicum), y que los alejandrinos enseguida apodaron "la Gran

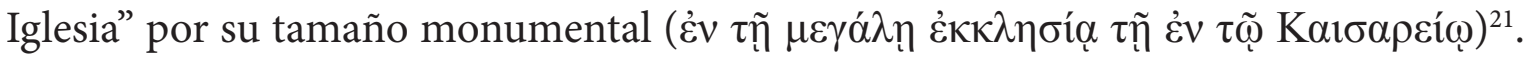
De forma curiosa y paradójica, las dos iglesias contuvieron sendos vestigios paganos sobresalientes: la de san Miguel guardaba el arquetipo sagrado del codo nilótico, y la Kyriakon, dos obeliscos que flanqueaban su entrada ${ }^{22}$. En nuestra opinión, ambos

20 En efecto, poco antes de referirse a la ley contra el clero andrógino adscrito al culto del Nilo,

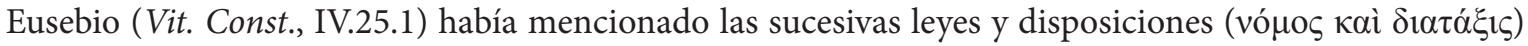
que Constantino había emitido prohibiendo "sacrificar a los ídolos, encargar oráculos, erigir simulacros, celebrar ritos ocultos y contaminar las ciudades con cruentas luchas de gladiadores", leyes que se concretaron en C.Th. IX.16.1-3. Por lo demás, hay evidencia de que los sacerdotes hermafroditas asociados al culto nilótico existían en la segunda mitad del s. IV, de manera que o bien no se aplicó la orden de Constantino, o ésta fue revocada después, quizás en época de Juliano (ver al respecto E. Moreno Resano, Constantino $y$ los cultos tradicionales, Zaragoza, 2008, pp. 319-320).

${ }^{21}$ Atan., Hist. Arian. ad mon., 55.2 y 74.2; idem, Apol. ad Const., 14 y 16; y JuAn DE Nikiou, Chron., 64 y 84.

${ }^{22}$ Los dos monolitos fueron levantados allí por Octavio Augusto, que los trajo desde Heliópolis en el año 13 a.C., y allí permanecieron decorando la entrada de la enorme iglesia cristiana hasta su definitivo desmantelamiento en el siglo X (Eutiquio, Ann., 501-503, PG III, 1149a). La historia de ambos obeliscos, 
vestigios - el codo y los obeliscos - simbolizan lo fácil y natural que le resultó al cristianismo egipcio asumir las formas externas del paganismo vernáculo (o quizá lo cómodo que se sentía entre ellas).

Ambas iglesias tuvieron quizás otro vínculo de mayor importancia para nuestro tema. Como ya se ha dicho, después de que Sócrates situara el venerado $\pi \tilde{\eta} \chi v \varsigma$ en el interior de una iglesia en época constantiniana, su coetáneo Sozomeno (V.3.3) afirmaba que el emperador Juliano el Apóstata ordenó devolverlo al Serapieion en un edicto fechado el 4 de febrero del año 362, en el cual se adoptaban también otras medidas de carácter más general que pretendían restaurar los antiguos cultos. A partir de aquí, y dado que no hay más alusiones al venerado codo salvo la indicación de Rufino (situándolo en una iglesia después del año 391), cabría pensar que éste quedó guardado en el templo de Serapis hasta el cierre definitivo del mismo, suceso a partir del cual el codo fue trasladado otra vez ${ }^{23}$. Pero hay otra opción más lógica a nuestro juicio.

Dado que la devoción popular al Nilo no decreció en absoluto con la implantación cristiana en el país, y dado que el artefacto tenía a estas alturas un valor simbólico muy notable, en algún momento posterior a la muerte del pagano emperador Juliano el codo sagrado pudo ser transferido a alguna de las iglesias de mayor relevancia que por entonces dominaban el paisaje urbano de Alejandría. Es probable que a la enorme Kyriakon, ya que se convirtió muy pronto en la "catedral" de la metrópoli (su sede episcopal), y a la que, de forma muy significativa, el obispo Atanasio consagró también a san Miguel cuando la reconstruyó en el año 368, después de los importantes daños que el edificio en su conjunto sufrió tras unas azarosas décadas de violencia religiosa en la ciudad ${ }^{24}$. Esto supondría concluir que el santo artefacto medidor de la crecida ya no se encontraba en el Serapieion cuando éste fue asaltado y cerrado posteriormente, en el año 391, y que Rufino equivocó la época del traslado al que se refirió en $H E$, II.30, que se habría producido necesariamente antes.

En beneficio de esta conjetura debemos señalar nuestra presunción de que las autoridades cristianas difícilmente hubieran permitido la destrucción o desaparición del codo sagrado durante los graves sucesos que condujeron al cierre del templo de Serapis en aquel año. Desde una perspectiva religiosa, se trataba de un objeto neutro que no podía atraer por sí mismo la ira e impiedad cristianas. Pero distinto era su valor simbólico, muy superior al religioso. En cierto sentido, el venerado artefacto estaba por encima de las diferencias religiosas que tenían dividida a la población alejandrina.

en J.-Y. Empereur, Alexandria rediscovered, Nueva York, 1998, pp. 112-122; y J.-L. ArnAuD, “Sources et méthodes de restitution. Les obélisques et le Césaréum d'Alexandrie”, en J.-Y. Empereur (ed.), Alexandrina, 2, 2002, 177-184. La historia del propio Caesareum se podrá ver en las referencias de la n. 24 infra.

${ }^{23}$ Tal es lo que creen algunos traductores y comentaristas de Sócrates y Sozomeno (ver A. J. FesTUgière, Sozomène. Histoire ecclésiastique, livre I, Paris, SC, 1983, p. 142 n. 2; y G. C. Hansen, Sócrates. Histoire ecclésiastique, livre I, Paris, SC, 2004, p. 182, n. 3), así como también F. E. EnGreEn, loc. cit., 3-13, y F. Thel amon, op. cit., p. 276, siguiéndose unos a otros. En esta hipótesis habría que asumir que el codo se salvó de las destrucciones y graves daños que sufrió el templo en el asalto cristiano conducido por Teófilo.

${ }^{24}$ Sobre la advocación a san Miguel de la iglesia reformada y reinaugurada en el año 368 por el obispo Atanasio ver O. F. A. Meinardus, loc. cit., p. 164, y J. McKenZIE, op. cit., pp. 240-242 y n. 25. La intensa historia de esta iglesia y del propio Caesareum en A. MARTIN, "Les premiers siècles du christianisme”, loc. cit., 218; idem, op. cit., pp. 472-473 y 564; Сн. HAAs, op. cit., pp. 143-144, 210-211, 283-285 y 313-323; H. Reinhard Seeliger, K. Krumeich, op. cit., pp. 47-49; y J. McKenzie, op. cit., pp. 177-178, 240-242, 406-409, nn. 25 y 97, y 411-412 n. 173. 
El codo servía a unos y otros, para todos era útil, tanto en un sentido meramente instrumental (arquetipo que garantizaba la medida correcta de los desbordamientos anuales) como ceremonial o religioso (símbolo de las bienhechoras crecidas). Precisamente por esta razón los cristianos ya lo habían tenido albergado en una iglesia, y por la misma razón Rufino quizá manipuló la fecha en la que el codo fue guardado en la iglesia del Señor (de las Aguas), es decir, la Kyriakon muy probablemente. Nosotros pensamos que de haberse encontrado alojado en las dependencias del Serapieion durante el asalto cristiano del 391, el obispo Teófilo, los miembros de la comunidad cristiana participantes en el ataque y pillaje del templo, y las autoridades civiles (cristianas), habrían intentado recuperar el artefacto e incluso exhibirlo y publicitarlo como símbolo inmediato de su victoria. Como ya apuntamos más arriba, imaginamos que fue a lo largo del reinado de Valente (364-378) que el sacrosanto codo - con toda su carga simbólica - pudo ser trasladado a la Kyriakon, justo en un periodo en el que, después de la muerte del emperador Juliano, y como testimonia Libanio (Or., XXX.7), se recrudeció la persecución contra el politeísmo; el traslado pudo producirse en el año 368, aprovechando la reconstrucción y reinauguración de la Gran Iglesia y su nueva advocación a san Miguel (vid. supra) ${ }^{25}$.

También se puede pensar que Rufino cometió el desliz cronológico de forma deliberada, justo para subrayar que el poder de Dios, y no el de Serapis, era el que creaba la crecida, y en este sentido decir una verdad a medias en lo que se refiere a la advocación religiosa de la iglesia que pasó a albergar el codo, o sea, la del "Señor [Kyriakon] de las Aguas" instalada en el témenos del viejo Caesareum. Obsérvese que las dos advocaciones conocidas de esta iglesia - del Señor y de san Miguel - se pueden equiparar, bien con el epíteto mencionado por Rufino (Señor de las Aguas, o sea, Dios), o bien con la advocación de la primera iglesia en la que estuvo alojado el instrumento nilométrico (san Miguel).

Las iglesias que acabamos de mencionar no fueron las únicas existentes en el paisaje urbano de Alejandría en el siglo IV. Sin duda es una tarea difícil seguir en la actualidad el rastro histórico de cualquiera de las levantadas allí desde los años finales del siglo III hasta casi el final del siglo IV $^{26}$. Ciertamente las fuentes literarias nos proporcionan los nombres de los obispos promotores y las advocaciones de muchas de ellas, incluso algunos detalles sobre sus ubicaciones, su desarrollo cronológico, etc., pero ningún resto arquitectónico significativo se ha preservado de casi ninguna

${ }^{25}$ La chispa que inició este recrudecimiento anti-pagano debió partir de sucesos como la revuelta del pagano Procopio (sofocada en el 366), o la ejecución del filósofo Máximo de Éfeso - antiguo amigo y consejero de Juliano -, colofón de una presunta conspiración contra Valente en el invierno del 371/372 (cf. A. H. M. Jones, op. cit., pp. 138-154; y L. Jerphagnon, Juliano el Apóstata, Barcelona, 2010, pp. 419-420).

${ }^{26}$ Se puede seguir este rastro en A. Rowe, B. R. ReEs, “The Great Serapeum of Alexandria”, Bulletin of the John Rylands Library, 39, 1957, 485-512, cit. 486-488; A. MARTin, "Alexandrie à l'époque romaine tardive: l'impact du christianisme sur la topographie et les institutions", en C. Décobert, J.-Y. Empereur (eds.), Alexandrie médièvale, vol. I, El Cairo, 1988, pp. 9-21; idem, "Les premiers siècles du christianisme", loc. cit., 211-225; J. GAscou, loc. cit., pp. 23-44; J. Kiss, "Alexandria in the fourth to seventh centuries", en R. S. Bagnall (ed.), Egypt in the Byzantine World, 300-700, Cambridge, 2007, pp. 187-206; y J. McKenzIE, op. cit., pp. 240-248. 
de ellas, bien por su posterior abandono y ruina irreversible, bien por el avance del mar en ciertas áreas de la ciudad, o bien por las reutilizaciones que sufrieron posteriormente. No obstante, la combinación de las fuentes escritas con las arqueológicas puede ofrecernos alguna información útil respecto a las formas y estructuras de estas primeras iglesias $^{27}$.

Es ciertamente desolador el informe referente a los restos arqueológicos de las iglesias alejandrinas más antiguas en el exhaustivo catálogo realizado recientemente por P. Grossmann (vid n. anterior). En efecto, la iglesia más antigua cuya ubicación y advocación religiosa se conoce bien es una erigida por el obispo Téonas (282-300) datada en el reinado del emperador Aureliano (270-275). Sabemos que se encontraba situada a la entrada de una extensa zona de catacumbas colindante al Puerto Occidental (Eunostos) y al Heptastadion, el viaducto que cruzaba el mar hasta la isla de Pharos y que arrancaba cerca de la "Puerta de la Luna", una de las entradas occidentales de la metrópoli en la que moría su arteria principal, la Vía Canópica ${ }^{28}$. La iglesia de Téonas, quizá reformada en aquella época, se convirtió en la residencia oficial del obispo de Alejandría hasta que la monumental Kyriakon la sustituyó en esa función en tiempos del emperador Constancio II.

Sabemos también que tras el fallecimiento del obispo Atanasio en el año 373, en la ciudad había no menos de 14 iglesias ${ }^{29}$. Más de la mitad de ellas fueron erigidas durante su episcopado, pero el ritmo de construcción de las mismas creció durante los mandatos de sus inmediatos sucesores, Timoteo I, Teófilo y Cirilo, casi todas erigidas ex novo y compitiendo aún con algunos templos paganos que seguían activos en la metrópoli, entre ellos los de Mitra, Dionisos (que fue reconvertido en iglesia por el obispo Teófilo), Perséfone (Koreion), Fortuna (Tychaion) y Serapis ${ }^{30}$. La extensa obra literaria del propio Atanasio y un listado confeccionado por el obispo chipriota Epifanio de Salamina (Panarion, 69.2.2-4, y 51.22.8-10), son fuentes muy útiles para el recuento de los edificios cristianos y paganos existentes en la ciudad hacia el año $380^{31}$.

De forma paradójica, el clausurado y arruinado Serapieion habría de aportar varias iglesias y capillas al recuento general posterior. Hay evidencia suficiente para pensar que en el 402 estaba ya construido un martyrium dentro de su antiguo témenos ${ }^{32}$. El dato encaja con el tamaño reducido del templo que había albergado la imagen de

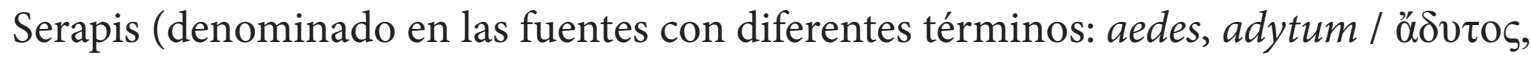
vaós, templum,...), el cual parece haber tenido sólo nueve metros de ancho ${ }^{33}$. Anejo al

${ }^{27}$ Recogidas en detalle en el trabajo de A. Martin, op. cit.; J. McKenzie, op. cit., pp. 230-232 y 244-253; y P. Grossmann, Christliche Architektur in Ägypten, Leiden, 2002.

${ }^{28}$ Cf. A. Martin, "Les premiers siècles du christianisme", loc. cit., 214; B. A. Pearson, "Earliest Christianity in Egypt: Some Observations", en B. A. Pearson, J. Goehring (eds.), The Roots of Egyptian Christianity, Philadelphia, 1986, pp. 132-159, cit. 152; P. Grossmann, op. cit., pp. 16-17, n. 1; H. ReInHard Seeliger, K. Krumeich, op. cit., pp. 49-50; J. McKenzie, op. cit., p. 240.

${ }^{29}$ Ver el recuento pormenorizado de J. McKenziE, op. cit., p. 244.

30 A. Martin, "Les premiers siècles du christianisme", loc. cit., 211-225.

31 A. Martin, op. cit., pp. 470-481.

${ }^{32}$ Este edificio albergó los huesos de San Juan Bautista que décadas atrás el emperador Juliano había enviado al obispo Atanasio desde Sebaste (Ruf., HE, II.27-28; JuAn DE Nikiou, Chron., 78.43-46). Más documentación sobre el edificio, la fecha y emplazamiento concreto, en J. McKenzie, op. cit., p. 409, n. 82.

${ }^{33}$ J. McKenziE, op. cit., p. 246. Como ocurría en todos los templos paganos, el edificio principal del témenos no estaba concebido - religiosa y arquitectónicamente hablando - para reunir o albergar en 
martyrium fue erigida una iglesia de nuevo cuño pero dentro del témenos del templo, la cual fue consagrada a S. Juan Bautista y a S. Elías, y que más adelante sería conocida con el nombre de Angelium o Evangelium (Ruf., HE, II.27-28; Soz., VII.15.10; Juan de Nikiou, Chron., 78.46, y 83.37) 34 . Fuera del témenos, pero adosadas al potente muro oeste que lo delimitaba, las excavaciones arqueológicas del siglo pasado hallaron restos de más iglesias erigidas en diferentes épocas ${ }^{35}$.

Así pues, a modo de resumen, podemos trazar algunas conclusiones sobre el tema:

1. Nuestras fuentes documentan no uno sino varios traslados del codo nilótico arquetípico en el siglo IV, y no una sino varias iglesias concernidas en ellos; al menos dos, considerando que Sócrates y Eutiquio por un lado, y Rufino por otro, se refirieron a iglesias diferentes.

2. Estas dos iglesias tuvieron advocaciones que pueden evocar el imaginario pagano relacionado con la crecida nilótica (v.g., san Miguel / Thot y el Señor de las Aguas / Khnum), y que a su vez pudieron coincidir con las de otra iglesia alejandrina, la Kyriakon, quizá la que Rufino mencionó bajo un título artificioso y muy intencionado.

3. El primer traslado del codo se produjo desde el Serapieion a una iglesia consagrada al arcángel san Miguel, y fue ordenado por el emperador Constantino

él a la comunidad de devotos del dios, sino sólo para guardar la imagen de culto y los "tesoros" (ofrendas) que se le consagraban, así como para plasmar en la decoración escultórica del mismo los eventos míticos asociados a la deidad. La acción cultual y los sacrificios se realizaban siempre en el exterior, junto a un altar dispuesto al efecto, o bien en lugares definidos por la tradición del culto o de la divinidad en cuestión. En el caso de los santuarios que poseían dentro de su témenos edificios grandes y largos pórticos, los cristianos los aprovecharon en su momento para convertirlos en iglesias y monasterios por razones económicas y prácticas obvias (J. R. AJA SÁNCHEZ, “Tolerancia religiosa romana e intolerancia cristiana en los templos del Alto Egipto: raíces y huellas”, Gerión, 25:1, 2007, 417-470), ya que las edificaciones cristianas sí estaban concebidas y destinadas para reunir y albergar a la congregación de creyentes. Por su parte, en el caso de los espacios y edificios paganos de menor tamaño, el cristianismo los aprovechó para convertirlos en capillas, oratorios y martyria. El témenos de Serapis, como tantos otros en la Antigüedad egipcia y grecorromana, encerraba un conjunto de estructuras de distinto carácter, sagradas, funcionales y meramente ornamentales.

${ }^{34}$ Este edificio sufriría distintos avatares hasta su definitiva destrucción en el siglo X (cf. A. RowE, B. R. ReEs, loc. cit., 503). El debate sobre las fechas y emplazamiento de esta iglesia y del martyrium anexo puede seguirse en estos mismos autores, y también en A. BADAwy, Coptic Art and Archaelogy, Cambridge (Mass.), 1978, p. 26; Thelamon, op. cit., pp. 264 ss; H. Heinen, "Alexandria in Late Antiquity", Coptic Encyclopedia, vol. I, 1991, pp. 99-101: 101; HaAs, op. cit., p. 207; J. McKenzie, S. Gibson, A. T. Reyes, "Reconstructing the Serapeum in Alexandria from the Archaelogical evidence", JRS, 94, 2004, 73-121; y J. McKenzie, op. cit., pp. 245-248.

${ }^{35}$ Los vestigios arquitectónicos de estas edificaciones y un número no pequeño de objetos procedentes de ellas han sido hallados en las excavaciones efectuadas a mediados del siglo XX y en los inicios del presente (J. McKenzie, S. Gibson, A. T. Reyes, loc. cit., 107-110). Hay constancia de que el ancho peristilo corrido que rodeaba el témenos del Serapieion, cuyos espacios internos probablemente habían albergado la biblioteca en época tardía, se conservó hasta que los árabes lo desmantelaron para aprovechar los tambores de las columnas como material de obra para los diques defensivos que levantaron en el puerto de Alejandría (ibid.). Igualmente, los suelos que formaban los cimientos de los edificios tampoco fueron tocados, pese a lo que sugiere Rufino (HE, II.27), dado el enorme volumen y peso de las piedras y bloques que los formaban según Eunapio (Vit. Soph., VI.11). 
a instancias del obispo Alejandro, al que más adelante le fue consagrada la misma iglesia.

4. Se produjo un segundo traslado en época del emperador Juliano, que ordenó devolver el codo a su lugar de origen, el templo de Serapis.

5. Pudo haber un tercer traslado después del año 391 (desde el Serapieion a una iglesia ignota consagrada al Señor de las Aguas), o bien en una fecha anterior (desde el mismo templo pagano a la Kyriakon durante el reinado de Valente). En cualquiera de los dos casos, el artefacto nilótico parece que estuvo alojado en este siglo en dos iglesias diferentes: en el primer tercio del siglo, en la constantiniana de san Miguel, y en el último tercio, o bien en la Kyriakon o bien en una ignota iglesia dedicada al "Señor de las Aguas".

6. A la hora de poder discernir cuál fue el caso correcto en la disyuntiva anterior, Rufino se nos muestra como el verdadero nudo gordiano del problema que afecta tanto a la identificación de la iglesia como a la época en la que se produjo el tercer y último traslado.

Abstract: Some later Roman sources placed the "nilotic cubit" inside some Christian churches and pagan sanctuaries of Alexandria during the fourth century. The sacred device was the ritual archetype of the unit of measure used by the Egyptians for measuring height of Nile flood every year. The aim of this paper is to check the reliability of those sources closely related to the Alexandrian cubit.

KEY wORDs: Later Roman Alexandria; nilotic cubit; literary sources. 